\title{
Ureteral strictures post-kidney transplantation: Trends, impact on patient outcomes, and clinical management
}

Michelle Minkovich ${ }^{1}$; Olusegun Famure ${ }^{1}$; Yanhong Li ${ }^{1}$; Anand Ghanekar ${ }^{1,2,3}$; Markus Selzner ${ }^{1,2}$; S. Joseph Kim ${ }^{* 1,4}$; Jason Y. Lee ${ }^{* 1,3}$

${ }^{1}$ Ajmera Transplant Centre, Toronto General Hospital, University Health Network, Toronto, ON, Canada; ${ }^{2}$ Division of General Surgery, University Health Network, Toronto, ON, Canada; ${ }^{3}$ Department of Surgery, Division of Urology, University Health Network, University of Toronto, Toronto, ON, Canada; ${ }^{4}$ Department of Medicine, Division of Nephrology, University Health Network, University of Toronto, Toronto, ON, Canada

${ }^{*}$ These authors co-directed this work

Cite as: Minkovich M, Famure O, Li Y, et al. Ureteral strictures post-kidney transplantation: Trends, impact on patient outcomes, and clinical management. Can Urol Assoc J 2021 March 18; Epub ahead of print. http://dx.doi.org/10.5489/cuaj.7003

Published online March 18, 2021

$* * *$

\section{Abstract}

Introduction: Ureteral strictures post-kidney transplantation (KT) can be a significant morbidity to the patient, often requiring surgical intervention and impacting graft function. We sought to investigate the incidence, clinical management, and outcomes of ureteral strictures among kidney transplant recipients (KTRs) at a large, multi-organ transplant center.

Methods: We conducted a single-center cohort study looking at KTRs who had transplant surgery from January 1, 2005 to March 31, 2017 with at least one-year followup (n=1742). Any KTRs done outside of our center or simultaneous multiorgan transplants were excluded. The Kaplan-Meier product-limit method was used to determine the incidence of ureteral strictures. Risk factors for ureteric strictures and clinical outcomes among patients with vs. without ureteric strictures were analyzed using Cox proportional hazards models.

Results: The incidence of ureteral strictures was 1.31 (95\% confidence interval [CI] $0.85,2.01)$ per 100 person-years or a cumulative incidence of $1.2 \%$. We did not find any donor or recipient demographic variables that were independently associated with an increased risk of ureteral stricture development. A large proportion was managed successfully with radiologic intervention alone (47.6\%). Ureteral strictures were associated with death-censored graft failure (hazard ratio [HR] 7.17, 95\% CI 2.81, 18.30), total graft failure (HR 3.04, 95\% CI 1.41, 6.59), and hospital readmission (HR 2.52, 95\% CI 1.58, 4.00). 
Conclusions: Although uncommon, ureteral strictures can significantly impact patient outcomes after KT. A better understanding of risk factors and clinical management will be important to ensure optimal graft outcomes.

\section{Introduction}

Kidney transplantation (KT) is the treatment of choice for most patients with end-stage renal disease (ESRD), providing improved quality of life and increased life expectancy for most patients. Nevertheless, KT is a complex surgical procedure associated with post-operative complications that can reduce the intended benefits. Urological complications, such as obstruction and urine leaks typically range in incidence from $3.4 \%$ to $10 \%{ }^{1-6}$ with some studies reporting an incidence as high as 14 to $20 \%{ }^{7-8}$ Aside from urinary tract infections, ureteral strictures are the most common urological complication following KT. ${ }^{9}$ Reported incidences range from 0.5 to $6.8 \%^{2-5,9-19}$ and the majority of cases occur within three months post KT. ${ }^{14,17,20}$ Early cases are thought to be related to surgical technique of KT or ischemic fibrosis, whereas later cases are attributed to ureteral fibrosis or compression by the surrounding fibrotic tissue. ${ }^{6}$

Some reported risk factors for ureteral strictures include older donor age ( $>65$ years), recipient male sex, kidneys with more than 2 arteries, delayed graft function, prolonged cold ischemia, fluid collections around the ureter, and BK virus infections. ${ }^{11,16-17,21-22}$ There is disagreement regarding the role of surgical technique as a risk factor, with some studies reporting a link, ${ }^{6,16-17,21}$ while others do not, ${ }^{23}$ and this may be related to whether a refluxing or non-refluxing anastomosis technique is utilized.

There is also a lack of consensus regarding the best clinical management for these complications. Some studies report immediate open surgical repair (surgical reimplantation of the ureter) as the gold standard and optimal first line of treatment, , 10,17,19-20 whereas other cohorts benefited more from minimally invasive treatments, such as percutaneous nephrostomy (PN) with balloon dilation. ${ }^{11,14,24}$ Yet others report no significant differences in the success or negative outcomes between the two types of interventions, calling for a case-by-case approach. ${ }^{16,25}$ Success rates of radiologic interventions and surgical interventions seem to be comparable at 71 to $86 \%$ and $80 \%$, respectively. ${ }^{26}$ For ureteral strictures occurring after the first 3 months of KT, however, some studies show a reduced long-term success rate of radiologic interventions - as low as $29 \%{ }^{21,26}$ to $50 \%$. ${ }^{6} \mathrm{~A}$ recent systematic review revealed success rates of $85.4 \%$ for open surgery, and $64.3 \%$ for radiologic interventions, as primary treatments. ${ }^{7}$ Among secondary treatments, open surgeries had a success rate of $93.1 \%$ versus $75.5 \%$ of radiologic interventions. ${ }^{7}$ Moreover, among patients receiving surgical repair, $19 \%$ require additional intervention, ${ }^{5}$ and there does not seem to be a significant difference in graft survival post radiologic or surgical treatment. ${ }^{5}$ 
Urological complications post KT, such as ureteral strictures, can be associated with graft dysfunction and graft loss. ${ }^{4}$ Ureteral strictures also have direct impacts on patient outcomes, particularly when surgical interventions are required, ${ }^{27}$ putting patients at risk for postoperative complications. That said, timely detection and appropriate management of ureteral strictures may prevent graft loss. ${ }^{16}$ Thus, it is imperative to improve the understanding and treatment of ureteral strictures post KT. Importantly, there remains a lack of consensus surrounding important information such as risk factors and best management practices which warrant further investigation. We sought to address these gaps by determining the incidence and trends of ureteral strictures, as well as examining the risk factors, clinical management, and patient outcomes of ureteral strictures in a large, single-centre cohort of kidney transplant recipients (KTR).

\section{Methods}

\section{Study design and population}

A single-centre, observational cohort study was conducted on adult KTR (aged 18 and older) transplanted between January 1st, 2005 and March 31st, 2017 with a minimum follow-up of one year. Eight surgeons were involved in the program during the study dates and ureteric stents were routinely used for all cases during the study period. Patients were excluded if they had prior non-kidney transplants, simultaneous multi-organ transplants or if their transplants were performed at other centres.

\section{Data sources}

Patient electronic medical records were reviewed for data abstraction, from our institution's Organ Transplant Tracking Record and Electronic Patient Record systems and the Comprehensive Renal Transplant Research Information System. ${ }^{28}$ This study received approval from our institution's research ethics board. Data was abstracted from clinical text documents and relevant diagnostic reports, such as Doppler ultrasound and biopsy reports. Adjudication of all suspected cases of ureteric strictures was performed by a transplant urologist (JYL).

\section{Data analyses}

In the first part of the analysis, ureteral strictures were examined as an outcome variable. Descriptive statistics were used to determine the incidence ureteral strictures and trends over time. Baseline recipient, donor, and transplant factors were summarized as mean values $( \pm$ standard deviation, SD) for continuous variables. Categorical variables were reported as frequencies and percentages. The incidence of ureteral strictures within one-year post-transplant was reported as a person-time incidence rate and as a cumulative probability using the KaplanMeier (KM) product limit estimator.

The analysis of risk factor analysis for ureteral strictures was conducted using univariable and multivariable Cox proportional hazards models. Some risk factors examined include 
recipient age and sex, medical history such as history of diabetes and vascular disease, number of arteries, delayed graft function, and induction type. An additional exploratory analysis was conducted to determine the effects of our centre's trends in stent removal times on ureteral strictures, using univariable Cox models.

Trends in time-to-resolution of ureteral strictures were examined and reported as the median number of days, with interquartile ranges at the 25 th and 75 th percentiles. Time-toresolution of ureteral strictures was separated by treatment type, i.e., radiologic intervention alone vs. surgery after failed radiologic intervention.

Clinical management of ureteral strictures was reported as percentages, stratified by donor type (living vs deceased). Treatments typically employed at our centre include standard ultrasound-guided PN, PN and balloon dilation (range 5-7 mm/ 15-21 Fr), and open surgical repair (either ureteral reimplantation or ureteroureterostomy using ipsilateral native ureter)

Ureteral strictures were also examined as an exposure variable in their relationship to clinical outcomes post-transplant. Clinical outcomes included death-censored graft failure, death with graft function, total graft failure (defined as a composite of the first two outcomes) and hospital readmissions within one-year post-transplant (defined as at least one overnight stay). The cumulative probabilities of the aforementioned clinical outcomes were examined using the KM product limit method. For univariable and multivariable analyses, Cox proportional hazards models were fitted to determine the association of ureteral strictures on post-transplant outcomes. Violations of the proportionality assumption were checked using $\log (-\log (\mathrm{S}(\mathrm{t})))$ plots and the interactions between the risk factors with time and Schoenfeld residuals. No important departures from proportionality were detected. Missing values in the Cox proportional hazard models were imputed using multiple imputation.

All analyses were performed using Stata/MP, version 12.0. ${ }^{29}$ A two-tailed p-value of $<$ 0.05 was considered statistically significant.

\section{Results}

\section{Study population}

After the application of the inclusion and exclusion criteria, the final study sample size was 1,742 KTR (Supplementary Figure 1). Over half of the population was male $(60.5 \%)$, white $(61.2 \%)$ and a little less than half $(46.3 \%)$ had a living donor. The mean recipient age was 51.3 \pm 13.4 years. The median follow up time of KTR was 1 year. Of the KTR with a deceased donor, $33.8 \%$ were expanded criteria donors (ECD). Table 1 shows the distribution of participant baseline characteristics. 


\section{Incidence and trends of ureteral strictures}

The incidence rate of ureteral strictures within the first year post-KT among our cohort was 1.31 (95\% CI: $0.85,2.01)$ per 100 person years, with a cumulative probability of ureteral strictures over the first-year post transplant of 1.2\% (Supplementary Figure 2). The total number of incident ureteral stricture cases was 21 , the majority of which $(61.9 \%)$ occurred within 3 to 6 months of KT (Supplementary Table 1). The vast majority of cases developed after KTR were discharged from their transplant admission (95.2\%). Incident cases were evenly distributed over the study cohort period, with 5 new cases (23.8\%) occurring in 2016 (as compared to 1 to 3 cases per year during other years) (Supplementary Figure 3).

An exploratory analysis examined proportions of ureteral strictures among the total number of transplants performed by each of our institution's surgeons. Proportions ranged from 0.0 to 0.5 , with no significant trends across different surgeons (Supplementary Table 2).

\section{Risk factors for ureteral strictures}

Variables reported to be associated with greater risk for ureteral strictures in the literature, such as recipient age, male sex, number of arteries, and induction type were not significantly associated with ureteral strictures among our cohort. Other risk factors explored, such as recipient race, BMI, and history of diabetes or vascular disease, did not yield any associations (Supplementary tables 3 and 4). An exploratory univariable analysis on the effect of length of stents post transplant on the incidence of first ureteral strictures revealed a significant association (HR: 1.06, 95\% CI: 1.05, 1.07).

\section{Clinical management of ureteral strictures}

While one patient had complete resolution of their stricture with NT alone, 9 (43\%) required a balloon dilation. Of these patients, four patients required two dilations. All five patients that had open surgical repair following NT only all had ureteral reimplantations, while 2 of the 5 patients that required open surgical repair following attempted interventional radiology management required ureteroureterostomy using the ipsilateral native ureter. Both patients requiring ureteroureterostomy had living donors. One patient that went on to have surgical repair following balloon dilation had only 1 attempted dilation, while the other 4 patients each had 2 attempts.

Among deceased donor KTR with ureteral strictures (11), six cases (54.4\%) were managed successfully with radiologic intervention alone, whereas $45.4 \%$ required open surgery following unsuccessful radiologic interventions. In contrast, $40 \%$ of living donor KTR with ureteral strictures (10) were managed successfully with radiologic intervention, while $60 \%$ needed surgery (Table 2).

\section{Time to resolution of ureteral strictures}

The median number of days to resolution of ureteral strictures with radiologic intervention, which included multiple radiologic interventions alone, and multiple radiologic attempts before going to surgery, was 128 (IQR: 90, 262). In contrast, the median number of days to resolution 
of cases resolved with open surgery after NT alone (i.e .no attempted balloon dilations) was 63 (IQR: 43, 65). This difference in time to resolution was significant $(\mathrm{p}=0.003)$.

\section{Clinical outcomes of ureteral strictures}

Ureteral strictures were significantly associated with death-censored graft failure (HR: 7.17, 95\% CI: $2.81,18.30$ ), total graft failure (HR: $3.04,95 \%$ CI: 1.41, 6.59) and hospital readmissions (HR: $2.52,95 \%$ CI: $1.58,4.00$ ). Death with graft failure showed no associations with ureteral strictures, in univariable (Figure 1 a-d) or multivariable (Table 3) models.

\section{Discussion}

Our centre's incidence rate of ureteral strictures of 1.31 (95\% CI: 0.85, 2.01) per 100 person years ( $1.2 \%$ of all KTR in the first year of follow-up), is comparable to that reported in the literature, which ranges from 0.5 to $6.8 \%$. The majority of cases occurred within the first three to six months post KT. Interestingly, commonly reported risk factors such as the number of arteries and induction type were not significantly associated with ureteral strictures in our cohort. Other baseline variables, such as recipient BMI or medical history, did not show any associations either. This may suggest that surgical technique-related factors may play a bigger role. However, exploratory analysis showed no significant differences in the proportions of KTR with ureteral strictures across our institution's KT surgeons. There may exist variables that are either not well captured or without the granularity required to discern risk factors associated with stricture development in our cohort of KTR, such as length of ureter utilized, tissue handling technique, etc. In addition, other factors related to institutional practices may have contributed to the incidence. For instance, an exploratory analysis revealed a significant, positive association between the length of stent dwelling and the risk of ureteral strictures, with a $6 \%$ increase in risk per day post transplant. This finding, while on univariable modelling only, may have implications for practice at our centre. Some studies do report lower rates of urological complications for earlier stent removal times of 2 weeks post transplant. ${ }^{4}$ At our centre, it is standard for KTR to have their stents removed at 4-6 weeks based upon availability of cystoscopy clinic time. Other factors that impacted this timeframe, however, include reasons such as missed appointments, development of UTI, or patient illness. We were unable to capture this granular data for each case in a valid manner, so could not provide analysis.

Descriptive statistics of clinical management practices at our centre suggest almost half of all KTR that develop ureteral strictures were successfully managed with IR intervention alone. Given the lower morbidity of this management approach compared to surgical ureteric reimplantation, this likely represents a reasonable first option. This seems particularly true for deceased donor KTRs. Though the data is limited by the low overall event rate, the rate of successful IR intervention alone was $54.5 \%$ for deceased KTR vs $40 \%$ for living donor KTR. In addition, while event rate was too low to perform statistical analysis, both patients that required ureteroureterostomy repair after attempted balloon dilation (due to increased length of stricture 
that made simple ureteral reimplantation unfeasible), had living donors. These findings may relate to the increased dissection of the ureter that often occurs during living donor nephrectomy, due to the need for mobilization of the gonadal vessels ${ }^{3}$. This suggests that perhaps living donor KTR that develop ureteral strictures might be best managed with early surgical repair. However, the small number of events among living donor KTR do not permit definitive conclusions.

Another finding from our study was that the time to resolution was significantly different between cases requiring multiple IR interventions (including those that eventually proceeded to open surgery) compared to those resolved with open surgery after only one failed radiologic intervention. This finding suggests using a more refined treatment algorithm whereby proceeding immediately to open reimplantation after only one failed IR intervention as opposed to multiple attempts at IR management of these strictures. However, given our low incidence, it is difficult to discern which patients would benefit most from an open vs an IR intervention up front.

Ureteral strictures post KT were significantly associated with death censored graft failure, total graft failure, and hospital readmissions. There was no association between ureteral strictures and death with graft failure. These findings emphasize the opportunity for improved surveillance and more timely management of ureteral strictures. Importantly, a ureteral stricture could potentially be a marker of a poor quality graft; whether it is inherent to the graft or recipient, it is crucial to gain a better understanding of its development and possible prevention. Though the incidence is low, the development of ureteral strictures, and perhaps the approach to management, seem to impact patient outcomes.

Some limitations of our study include its single-centre, retrospective design and the varied documentation of ureteral strictures in patients' medical records. However, our transplant patient population is one of the largest and most diverse cohorts in North America, allowing for generalizability of results. To combat the latter limitation, consultations were held with our centre's transplant urologist to adjudicate cases. Another major limitation is the lack of granularity with respect to certain variables of interest. For patients managed with balloon dilations, various sizes of balloon dilators were used (15-21 Fr) but we did not have details on why these variations existed as it was at the discretion of the interventional radiologist of the day. Also, while all surgeons used a refluxing technique for ureteral anastomosis during KT, granular details on length of ureter used, degree of tissue handling and trauma were not available. These details could play a significant role in ureteral stricture formation. Our study also only included 1-year of post-KT follow-up for the outcome of ureteral strictures. KTR that developed ureteral strictures more than 1-year from the time of KT were not captured in our analysis and so we are unable to characterize the incidence, risk factors, and management outcomes for those delayed presentations. Some of our analyses could not be done with multivariate models due to lack of events or data, warranting further research.

Recommendations for future research include more closely examining the effects of surgical technique on ureteral strictures. A comprehensive cost analysis of ureteral strictures may 
provide insight as to which interventions should be the first line of treatment and for which patient population. Finally, some studies have explored alternative forms of treatment such as the thermo-expandable Memokath stent,$^{30}$ and surgical interventions using an artificial ureter. ${ }^{26}$ It would be worthwhile to further explore these options in larger populations.

\section{Conclusions}

This large single-centre cohort of KTR demonstrated that the incidence of ureteral strictures is low but that it can significantly impact patient and graft outcomes post kidney transplantation. While no clear risk factors were found in our cohort, surgical technique may have played a significant factor. While a large proportion of patients can be managed successfully with minimally invasive radiologic procedures, a better understanding of which patients will ultimately require definitive open surgical repair is also imperative. Our data suggests living donor KTRs might be better managed with open repair, but further study is required. 


\section{References}

1. Krajewski W, Dembowski J, Kołodziej A, et al. Urological complications after renal transplantation - a single centre experience. Cent European J Urol 2016 69:306-11. Doi: $10.5173 /$ ceju. 2016.833

2. Hotta K, Miura M, Wada Y, et al. Original Article : Clinical Investigation Atrophic bladder in long-term dialysis patients increases the risk for urological complications after kidney transplantation. Int J Urol 2017:6-11. doi:10.1111/iju.13297

3. Pourmand G, Mehrsai AR, Taheri M. Evaluation of endourological interventions used to treat urological complications in 394 kidney recipients. Transplant Proc 2000;525:52425.

4. Harza M, Baston C, Preda A, et al. Impact of ureteral stenting on urological complications after kidney transplantation surgery: A single-center experience. Transplant Proc 2014;46(10):3459-62. doi:10.1016/j.transproceed.2014.08.051

5. Arpali E, Al-Qaoud T, Martinez E, et al. Impact of ureteral stricture and treatment choice on long-term graft survival in kidney transplantation. Am J Transplant 2018;(June 2017):1977-85. doi:10.1111/ajt.14696

6. Boyvat, F., Aytekin, C., Colak, T. et al. Memokath Metallic Stent in the Treatment of Transplant Kidney Ureter Stenosis or Occlusion. Cardiovasc Intervent Radiol 2005; 28: 326-30.

7. https://doi-org.uhn.idm.oclc.org/10.1007/s00270-004-0028-2

8. Kwong J, Schiefer D, Aboalsamh G, Archambault J, Luke PP. Optimal management of distal ureteric strictures following renal transplantation : a systematic review. Transp Int 2016;29: 579-88. doi:10.1111/tri.12759

9. Sabnis RB, Singh AG, Ganpule AP, Chhabra JS, Tak GR, Shah JH. The development and current status of minimally invasive surgery to manage urological complications after renal transplantation. Indian Journal of Urology: IJU : Journal of the Urological Society of India. 2016;(3):186-91. Doi: 10.4103/0970-1591.185100

10. Tran H, Arsovska O, Paterson RF, Chew BH. Evaluation of risk factors and treatment options in patients with ureteral stricture disease at a single institution. CUAJ 2015;9:921-24. Doi: 10.5489/cuaj.3057

11. Abdo N, Murez T, Cabaniols L, et al. Results of surgical revisions for ureteral complications after renal transplantation. Progres en Urologie : Journal de L'association Francaise D'urologie et de la Societe Francaise D'urologie 2019 29:474-81. DOI: 10.1016/j.purol.2019.05.010.

12. Fontana I, Bertocchi M, Rossi AM, et al. Late ureteral stenosis after kidney transplantation : A single-center experience. TPS 2010;42:1174-75. doi:10.1016/j.transproceed.2010.03.053

13. Balaban M, Ozkaptan O, Sevinc C, Karadeniz T. Minimally invasive approach to ureteral stricture in transplant kidney by periodic retrograde ureteral stent placement and exchange. Transplant Proc 2018;50:3405-10. doi:10.1016/j.transproceed.2018.06.029

14. Schult M, Brunkhorst R. Native pyeloureterostomy after kidney transplantation : experience in 48 cases. Transplant Int 2000; 13: 340-43. Doi: 10.1007/s001470050711 
15. Uflacker A, Sheeran D, Khaja M, Patrie J, Elias G, Saad W. Outcomes of percutaneous management of anastomotic ureteral strictures in renal transplantation : Chronic nephroureteral stent placement with and without balloon dilatation. Cardiovasc Intervent Radiol 2015:693-701. doi:10.1007/s00270-014-0952-8

16. Mano R, Golan S, Holland R, Livne PM, Lifshitz DA. Endourology and stones retrograde endoureterotomy for strictures in renal transplant kidneys. Urology 2012;80:255-59. doi:10.1016/j.urology.2012.02.030

17. Gil-Sousa D, Oliviera-Reis D, Teves F, et al. Ureteral stenosis after renal transplantationA single-center 10-year experience. Transplant Proc 2017;49:777-82. doi:10.1016/j.transproceed.2017.01.050

18. Pike TW, Pandanaboyana S, Hope-johnson T, Hostert L, Ahmad N. Ureteric reconstruction for the management of transplant ureteric stricture : a decade of experience from a single centre. Transp Int 2015;28: 529-34. doi:10.1111/tri.12508

19. Emiroglu R, Karakyall H, Sevmis S, Akkoc H, Bilgin N, Haberal M . Urologic Complications in 1275 Consecutive Renal Transplantations. Transplant Proc 2001; 33: 2016-17.

20. Doehn C, Böse N, Meyer A, Jocham D. Whose transplant function fails after ureteral revision following kidney transplantation? TPS 2010;42:1716-18. doi:10.1016/j.transproceed.2010.01.075

21. Kroczak T, Koulack J, Mcgregor T. Management of complicated ureteric strictures after renal transplantation: Case series of pyelovesicostomy with Boari flap. Transplant Proc 2015;47:1850-53 doi:10.1016/j.transproceed.2015.02.020

22. Azhar RA, Hassanain M, Aljiffry M, et al. Successful salvage of kidney allografts threatened by ureteral stricture using pyelovesical bypass. Am J Transplant 2010:141419. doi:10.1111/j.1600-6143.2010.03137.

23. Srinivasan D, Stoffel JT, James C, Bradley K, Sung RS. Outcomes of kidney transplant recipients with percutaneous ureteral interventions : A single center study. Transplant Direct 2017;3:1-7. doi:10.1097/TXD.0000000000000637

24. Ameer A, Aljiffy M, Jamal M, et al. Complications of ureterovesical anastomosis in adult renal transplantation : Comparison of the Lich-Gregoire and the Taguchi techniques. Ann Transplant 2011;16:82-7.

25. Asadpour A, Molaei M, Yaghoobi S. Management of ureteral complications in renal transplantation: Prevention and treatment. Saudi J Kidney Dis Transpl 2011;22:72-4.

26. Simsek C, Dogan SM, Piskin T, et al. Should interventional radiology or open surgery be the first choice. Transplant Proc 2017;49:517-22. doi:10.1016/j.transproceed.2017.01.018

27. Andonian S, Zorn KC, Paraskevas S, Anidjar M. Artificial ureters in renal transplantation. Urology 2005; 66: 9-11. doi:10.1016/j.urology.2005.05.012

28. Berli JU, Montgomery JR, Segev DL, et al. Surgical management of early and late ureteral complications after renal transplantation : techniques and outcomes. Clin Transplant 2015; 29:26-33. doi:10.1111/ctr.12478 
29. Li GJ, Trac J, Husain S, Famure O, Li Y, Joseph Kim S. Incidence, risk factors, and outcomes of Clostridium difficile infections in kidney transplant recipients.

Transplantation 2018;102:1576-81. doi:10.1097/TP.0000000000002199

30. StataCorp. Stata Statistical Software: Release 12. College Station, TX: StataCorp LP. 2011

31. Bach C, Kabir MN, Goyal A, et al. A self-expanding thermolabile nitinol stent as a minimally invasive treatment alternative for ureteral strictures in renal transplant patients. Journal of Endourology 2013;27:1543-45. DOI: 10.1089/end.2013.0180.

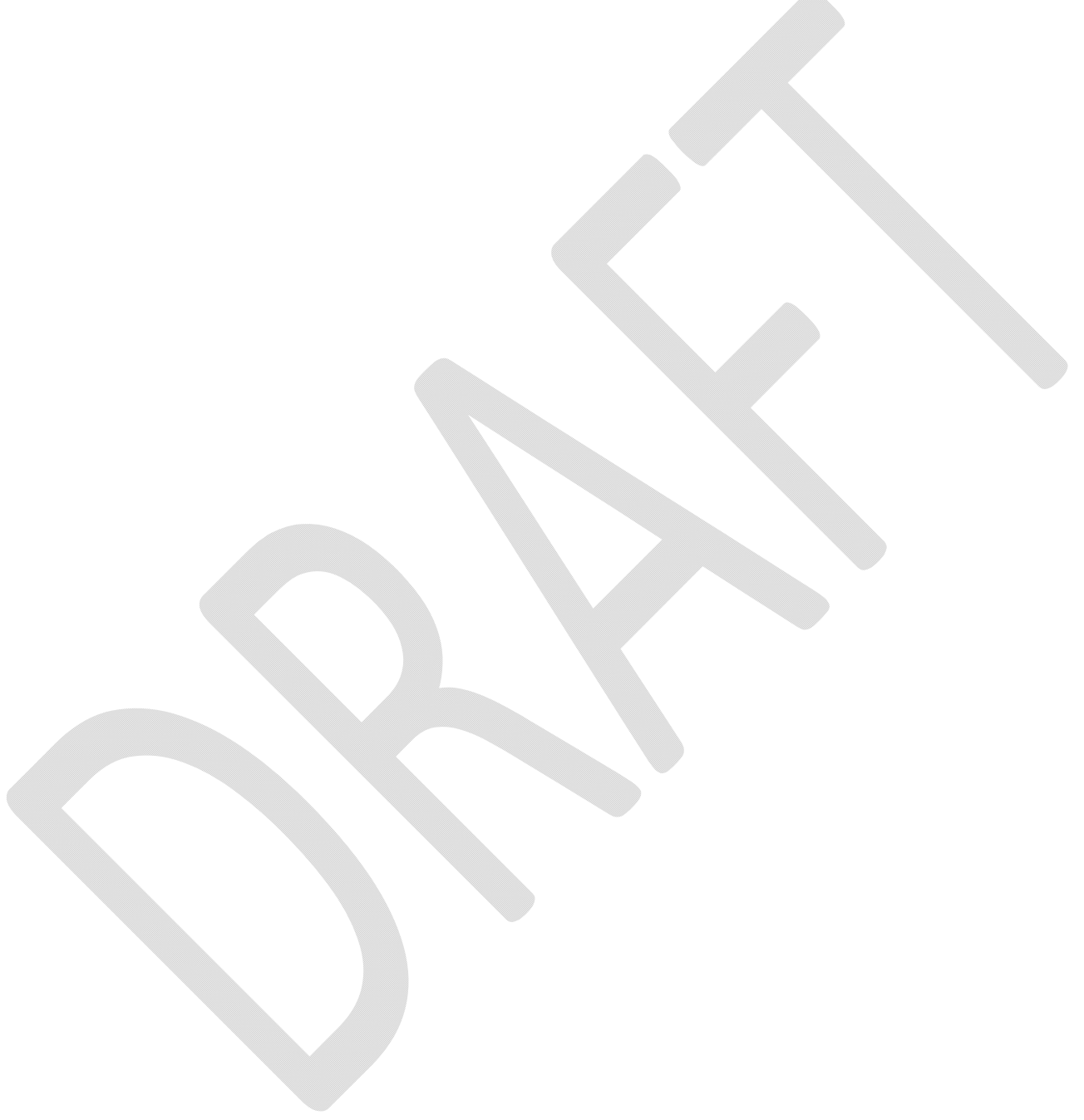




\section{Figures and Tables}

Fig. 1. Cumulative probability of $(\boldsymbol{A})$ death-censored graft failure; $(\boldsymbol{B})$ death with graft function; (C) total graft failure; and (D) hospital re-admissions; separated by presence/absence of ureteral strictures.
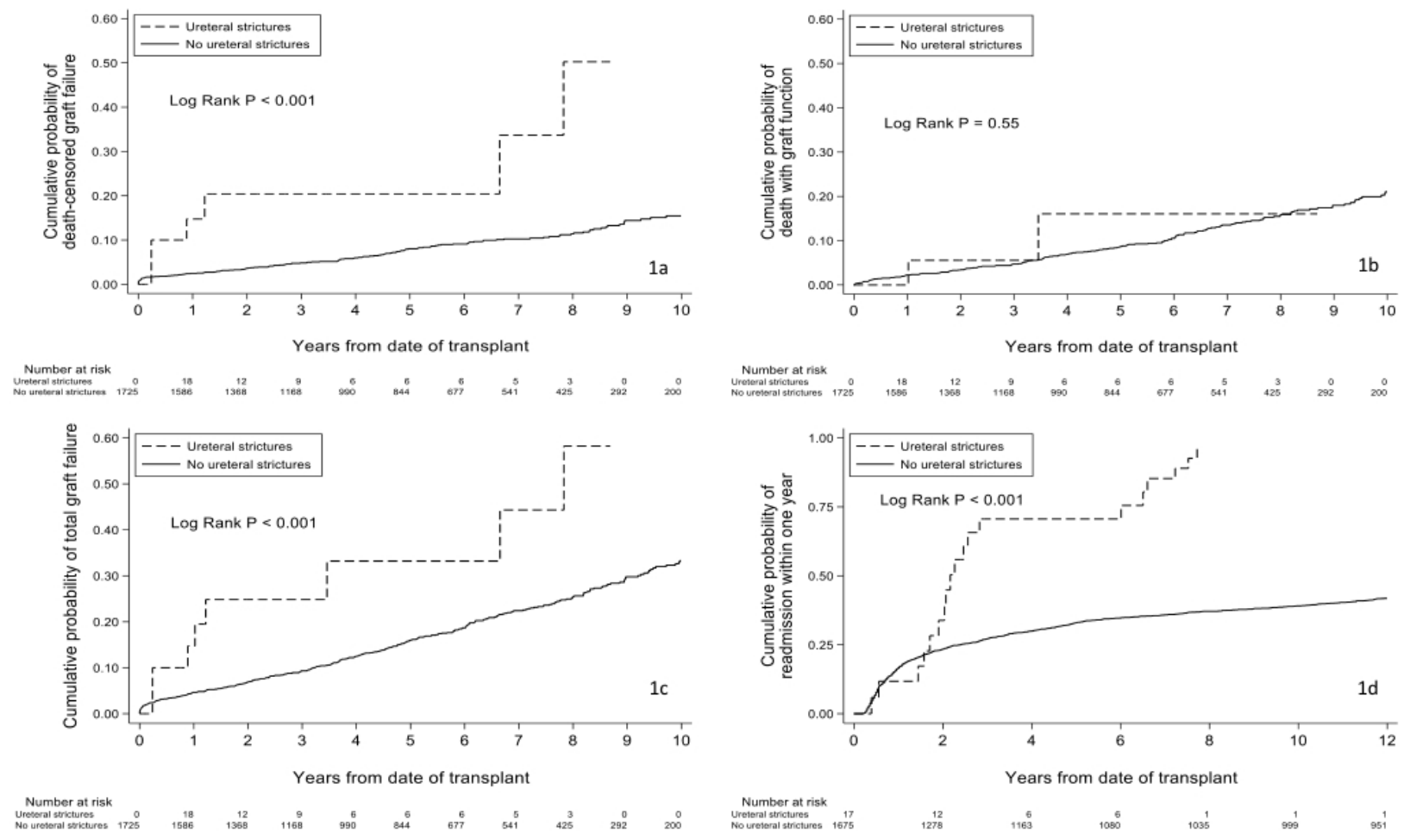


\begin{tabular}{|c|c|c|}
\hline Variables & $\begin{array}{c}\text { Number of } \\
\text { transplants } \\
(n=1742)\end{array}$ & $\begin{array}{c}\text { Characteristics } \\
\text { n (\%) }\end{array}$ \\
\hline Mean KTR age at transplant (years) & 1742 & $51.3 \pm 13.4$ \\
\hline \multicolumn{3}{|l|}{ Recipient sex } \\
\hline Female & 1053 & $689(39.5 \%)$ \\
\hline \multicolumn{3}{|l|}{ Recipient race } \\
\hline Non-white & 591 & $591(38.8 \%)$ \\
\hline White & 931 & $931(61.2 \%)$ \\
\hline \multicolumn{3}{|l|}{ Recipient history of vascular disease } \\
\hline No & 1250 & $1250(72.0 \%)$ \\
\hline \multicolumn{3}{|l|}{ Peak PRA } \\
\hline $0 \%$ & 840 & $840(48.3 \%)$ \\
\hline$>0 \%$ & 899 & $899(51.7 \%)$ \\
\hline Mean donor age at donation (years) & 1733 & $47.4 \pm 14.5$ \\
\hline \multicolumn{3}{|l|}{ Donor type } \\
\hline Deceased (Non-ECD) & 619 & $619(35.5 \%)$ \\
\hline Deceased (ECD) & 316 & $316(18.1 \%)$ \\
\hline Living & 807 & $807(46.3 \%)$ \\
\hline \multicolumn{3}{|l|}{ Delayed graft function } \\
\hline No & 1363 & $1363(78.2 \%)$ \\
\hline \multicolumn{3}{|l|}{ Number of veins } \\
\hline 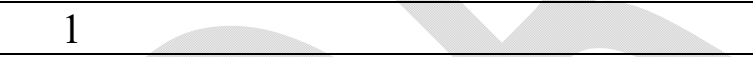 & 1604 & $1604(94.0 \%)$ \\
\hline$>1$ & 103 & $103(6.0 \%)$ \\
\hline \multicolumn{3}{|l|}{\begin{tabular}{|l|l|} 
Number of arteries \\
\end{tabular}} \\
\hline 1 & 1356 & $1356(79.3 \%)$ \\
\hline 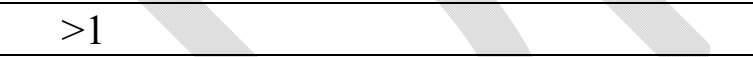 & 355 & $355(20.7 \%)$ \\
\hline $\begin{array}{l}\text { Mean cold ischemic time (deceased only) } \\
\text { (hours) }\end{array}$ & 867 & $10.9(14.8,7.9)$ \\
\hline \multicolumn{3}{|l|}{ Induction type } \\
\hline Non-depleting agent, e.g., basilixumab & 424 & $424(24.3 \%)$ \\
\hline Depleting agent, e.g., ATG & 1308 & $1308(75.1 \%)$ \\
\hline
\end{tabular}

ATG: antithymocyte globulin; ECD: expanded criteria donors; KTR: kidney transplant recipients; PRA: panel-reactive antibodies. 


\begin{tabular}{|l|c|c|c|c|c|}
\hline Table 2. Treatment of ureteral strictures, separated by donor type \\
\hline \multirow{2}{*}{$\begin{array}{l}\text { Donor } \\
\text { type }\end{array}$} & $\begin{array}{c}\text { Perc } \\
\text { nephrostomy } \\
\text { only }\end{array}$ & $\begin{array}{c}\text { Perc nephrostomy } \\
\text { balloon dilation } \\
\text { only }\end{array}$ & $\begin{array}{c}\text { Treatment categories } \\
\text { nephrostomy } \\
\text { surgery }\end{array}$ & $\begin{array}{c}\text { Perc nephrostomy + } \\
\text { balloon dilation + } \\
\text { surgery }\end{array}$ & Total \\
\hline Deceased & $1(9.09 \%)$ & $5(45.45 \%)$ & $4(36.36 \%)$ & $1(9.09 \%)$ & $11(100 \%)$ \\
\hline Living & $0(0 \%)$ & $4(40.00 \%)$ & $2(20.00 \%)$ & $4(40.00 \%)$ & $10(100 \%)$ \\
\hline Total & $1(4.76 \%)$ & $9(42.86 \%)$ & $6(28.57 \%)$ & $5(23.81 \%)$ & $21(100 \%)$ \\
\hline
\end{tabular}

Table 3. Multivariable Cox proportional hazard models for the effects of ureteral strictures on clinical outcomes post transplantation

\begin{tabular}{|l|c|c|c|c|c|c|c|c|}
\hline & \multicolumn{9}{|c|}{ Transplant outcomes } \\
\cline { 2 - 8 } & $\begin{array}{c}\text { Death-censored graft } \\
\text { failure }\end{array}$ & \multicolumn{2}{|c|}{$\begin{array}{c}\text { Death with graft } \\
\text { function }\end{array}$} & \multicolumn{2}{c|}{ Total graft failure } & \multicolumn{2}{|c|}{$\begin{array}{c}\text { Hospital re- } \\
\text { admission }\end{array}$} \\
\cline { 2 - 9 } & $\begin{array}{c}\text { HR } \\
(\mathbf{9 5 \%} \text { CI) }\end{array}$ & $\mathbf{p}$ & $\begin{array}{c}\text { HR } \\
\mathbf{( 9 5 \%} \text { CI) }\end{array}$ & $\mathbf{p}$ & $\begin{array}{c}\text { HR } \\
\mathbf{( 9 5 \%} \mathbf{C I})\end{array}$ & $\mathbf{p}$ & $\begin{array}{c}\text { HR } \\
\mathbf{( 9 5 \%} \mathbf{C I})\end{array}$ & $\mathbf{p}$ \\
\hline $\begin{array}{l}\text { Ureteral } \\
\text { strictures (yes } \\
\text { vs. no) }\end{array}$ & $\begin{array}{c}7.17 \\
(2.81,18.30)\end{array}$ & $<0.001$ & $\begin{array}{c}1.21 \\
(0.29,5.00)\end{array}$ & 0.79 & $\begin{array}{c}3.04 \\
(1.41,6.59)\end{array}$ & 0.001 & $\begin{array}{c}2.52 \\
(1.58,4.00)\end{array}$ & $<0.001$ \\
\hline
\end{tabular}

CI: confidence interval; HR: hazard ratio. 